\title{
Dysregulated Tim-3 expression on natural killer cells is associated with increased Galectin-9 levels in HIV-1 infection
}

Stephanie Jost ${ }^{1}$, Uriel Y Moreno-Nieves ${ }^{1}$, Wilfredo F Garcia-Beltran ${ }^{1}$, Keith Rands ${ }^{1}$, Jeff Reardon ${ }^{1}$, Ildiko Toth ${ }^{1}$, Alicja Piechocka-Trocha ${ }^{1}$, Marcus Altfeld ${ }^{1,2}$ and Marylyn M Addo ${ }^{1 *}$

\begin{abstract}
Background: Natural killer (NK) cells constitutively express high levels of Tim-3, an immunoregulatory molecule recently proposed to be a marker for mature and functional NK cells. Whether HIV-1 infection modulates the expression of Tim-3 on NK cells, or the levels of its ligand Galectin-9 (Gal-9), and how signaling through these molecules affects the NK cell response to HIV-1 remains inadequately understood.

Results: We analyzed Tim-3 and Gal-9 expression in a cohort of 85 individuals with early and chronic HIV-1 infection, and in 13 HIV-1 seronegative control subjects. HIV-1 infection was associated with reduced expression of Tim-3 on NK cells, which was normalized by HAART. Plasma concentrations of Gal-9 were higher in HIV-1-infected individuals than in healthy individuals. Interestingly, Gal-9 expression in immune cells was significantly elevated in early infection, with monocytes and dendritic cells displaying the highest expression levels, which correlated with HIV-1 viral loads. In vitro, Gal-9 triggered Tim-3 downregulation on NK cells as well as NK cell activation.

Conclusions: Our data suggest that high expression levels of Gal-9 during early HIV-1 infection can lead to enhanced NK cell activity, possibly allowing for improved early control of HIV-1. In contrast, persistent Gal-9 production might impair Tim-3 activity and contribute to NK cell dysfunction in chronic HIV-1 infection.
\end{abstract}

Keywords: Tim-3, Gal-9, HIV-1, Innate immunity, NK cells

\section{Background}

The human immunodeficiency virus type 1 (HIV-1) affects 34 million adults and children worldwide, and the ongoing spread of the epidemic resulted in about 2.5 million new infections and 1.7 million deaths in 2011 alone [1]. Novel approaches to prevent the transmission of HIV-1 are urgently needed, and whether manipulating innate immune effector cell function could be used as a strategy to enhance HIV-1 vaccine efficiency remains to be determined. Recent data suggest that incorporating components with the potential to harness the antiviral function of natural killer (NK) cells may represent an attractive option to improve future vaccine designs [2-13].

NK cells play an important role in containing viral replication in the very early stages of viral infections,

\footnotetext{
*Correspondence: maddo@partners.org

'Ragon Institute of MGH, MIT and Harvard, 400 Technology Square,

Cambridge, MA 02139, USA

Full list of author information is available at the end of the article
}

and in shaping the subsequent adaptive immune response by interacting with other immune cells, including dendritic cells (DCs) and CD4+ T cells [14-17]. NK cell function is regulated by the integration of inhibitory and activating signals generated by an arsenal of cell surface receptors, with effector functions taking place when activating signals overcome inhibitory ones [18]. Importantly, mounting evidence suggests that NK cells can mediate antiviral activity in HIV-1-infected humans [2-12]. However, how NK cells recognize and eliminate HIV-1-infected cells and control HIV-1 replication and disease progression remains poorly understood to date.

It has recently been described that NK cells constitutively express high levels of T-cell immunoglobulin and mucin domain-containing molecule 3 (Tim-3) [19-21]. Tim-3 is a type I transmembrane receptor that is also expressed on specific subsets of CD4+ and CD8+ T cells,

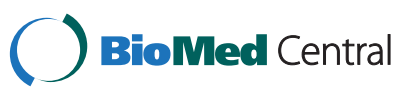


on subpopulations of macrophages and DCs, and on monocytes (reviewed in [22]), albeit to a lesser extent than on NK cells [19]. Tim-3 was originally identified as a marker of terminally differentiated CD4+ Th1 cells [23], and subsequently associated with T-cell exhaustion and impaired virus-specific T-cell responses in HIV-1, hepatitis $\mathrm{C}$ virus $(\mathrm{HCV})$ and hepatitis $\mathrm{B}$ virus (HBV) infection [24-28]. To date, three ligands have been described for Tim-3, including Galectin-9 (Gal-9), a 40-kD S-type $\beta$-galactoside-binding lectin [29], cell-surface phosphatidylserine [30,31], and-at least in murine models-the high-mobility group box 1 (HMGB1) protein [32]. Gal-9 is highly expressed in immune tissues [33], and while engagement of Tim-3 triggers apoptosis in CD4+ Th1 cells [29], T cells and thymocytes [34], this interaction has been suggested to (i) protect activated CD4+ T cells from HIV-1 infection and replication [35], (ii) enhance the production of pro-inflammatory cytokines by immature dendritic cells [36,37] and (iii) regulate the migration of Th2 cells [38]. Therefore, Tim-3 signaling on immune cells can trigger either inhibitory or activating signals, with the outcome depending on the presence of described and potentially as yet undefined ligands for Tim-3 [39]. While Tim-3 has been extensively studied on $\mathrm{T}$ cells, much less is known about the impact of Tim-3-mediated signaling on NK cell responses, notably in the context of viral infections.

Expression of Tim-3 can be induced on NK cells by various cytokines $[20,21]$, and Tim-3 has recently been proposed to be a marker for mature and fully functional NK cells, with those expressing the highest levels of the receptor displaying the most potent cytotoxic activity or cytokine production [21]. On NK cells, Tim-3 can act as an activating co-receptor, as exposure to Gal-9 enhances IFN- $\gamma$ production by Tim-3+ NK cells [20], yet it can also deliver inhibitory signals, given that the ability of NK cells to kill target cells is lost upon Tim-3 crosslinking [21]. In accordance with the latter observation, up-regulation of Tim-3 on NK cells has been associated with reduced anti-viral properties in chronic hepatitis B infection, with NK cell cytolytic function being enhanced upon Tim-3 blockade [40].
Progressive HIV-1 infection leads to significant changes in NK cell phenotype and function, and is associated with an expansion of anergic NK cells [41,42]. However, it is not known whether chronic HIV-1 infection modulates the expression of Tim-3 on NK cells or the levels of its ligand Gal-9, nor is it understood how signaling through these molecules affects the NK cell response to HIV-1. Here, we describe dysregulated expression of Tim-3 on NK cells in HIV-1 infection, with differential responses in early versus chronic HIV-1 infection. Plasma levels of Gal-9 were elevated in HIV-1 -infected individuals and correlated with markers of HIV-1 disease progression. Moreover, we show that stimulation of Tim-3+ NK cells by Gal-9 leads to NK cell activation and Tim-3 downregulation in vitro. Our data suggest that persistent signaling through Tim-3 on NK cells might result in loss of functionality and accumulation of a Tim- $3^{\text {low }}$ NK cell population in vivo, thereby contributing to the previously described impaired activity of NK cells in chronic HIV-1 infection.

\section{Results}

HIV-1 infection is associated with decreased percentages of Tim-3+ NK cells

The immunoregulatory molecule Tim-3, previously associated with $\mathrm{T}$ cell exhaustion and anergy, was recently shown to mark NK cell maturation and to suppress cellmediated toxicity [21]. As progressive HIV-1 infection leads to the accumulation of dysfunctional NK cells $[41,42]$, we first examined whether surface expression of Tim-3 protein on NK cells was altered in individuals at different stages of HIV-1 infection when compared to healthy subjects (Table 1). As demonstrated in previous studies, our data highlight a high degree of variation between the frequencies of Tim-3-expressing NK cells in HIV-1 negative individuals (median, 73.36; interquartile range [IQR], 57.80-80.14) [21] (Figure 1). Similar heterogeneity of Tim-3 expression on NK cells was observed in HIV-1-infected individuals (median, 59.77; IQR, 47.80-66.04), yet percentages of Tim-3+ NK cells were significantly decreased in HIV-1 infection compared to

Table 1 Characteristics of HIV-1-infected study participants and healthy controls

\begin{tabular}{lccccc}
\hline Cohort & N & $\begin{array}{c}\text { Median viral load } \\
\text { (RNA cop/mL) }\end{array}$ & $\begin{array}{c}\text { IQR viral load } \\
\text { (RNA cop/mL) }\end{array}$ & $\begin{array}{c}\text { Median CD4+ cell count } \\
\text { (cells/mm3) }\end{array}$ & $\begin{array}{c}\text { IQR CD4+ cell count } \\
\text { (cells/mm3) }\end{array}$ \\
\hline HIV negative & 13 & & & & 502 \\
Early infection & 14 & 51200 & $1383-142500$ & 547 & $425-688$ \\
Chronic untreated & 20 & 8137 & $5664-21175$ & 558 & $354-712$ \\
Chronic treated & 17 & $<50$ & & 803 & $654-1224$ \\
Elite controllers & 17 & $<50$ & & 581 & $452-843$ \\
Viremic controllers & 17 & 382 & $193-884$ & & \\
\hline
\end{tabular}

IQR interquartile range. 

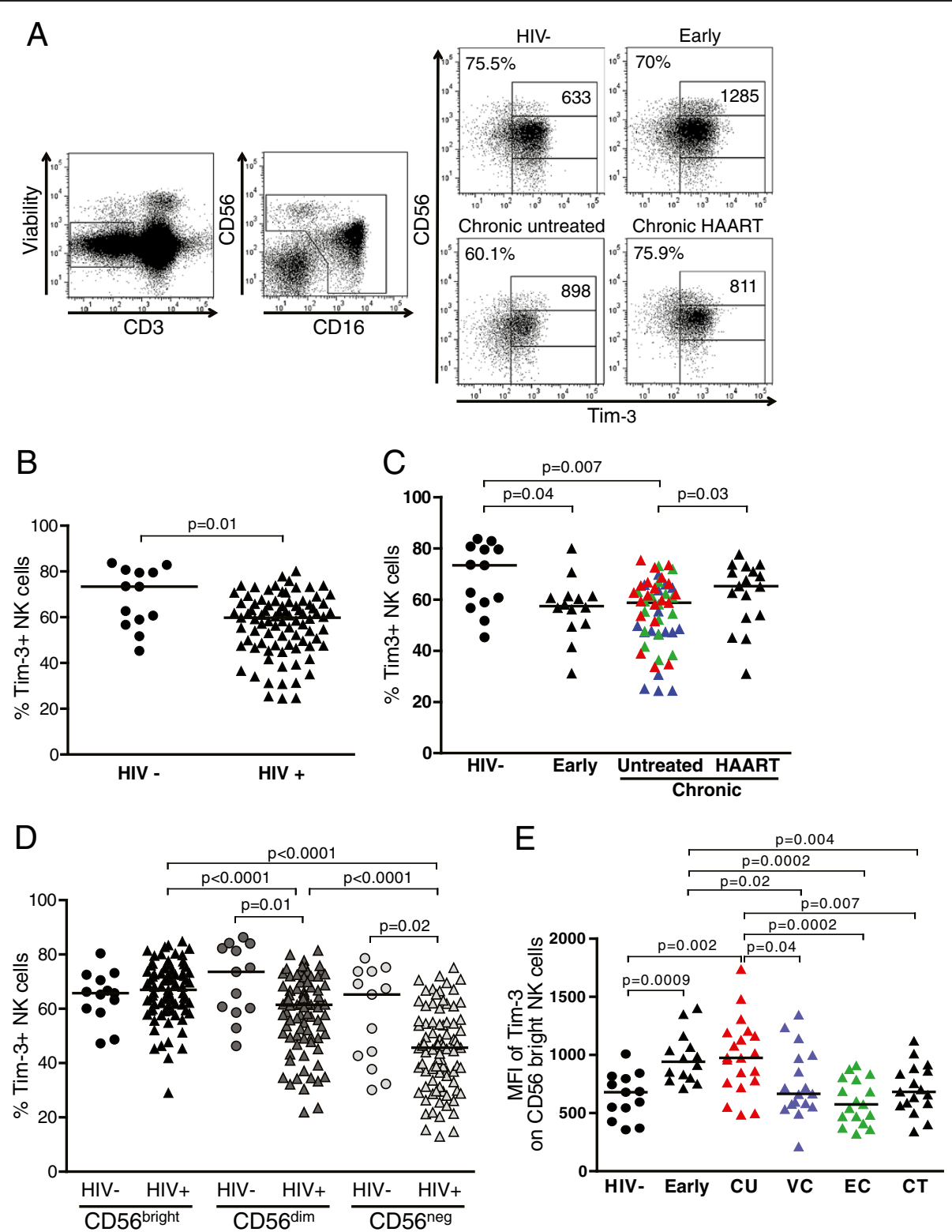

Figure 1 Tim-3 expression is dysregulated in HIV-1 infection. (A) Flow cytometry gating strategy: Gates are set to include CD3- lymphocytes and exclude dead cells (viability marker ${ }^{+}$). NK cell subsets are defined by the expression of CD56 and CD16, and Tim-3+ NK cells by using appropriate fluorescence-minus-one controls. The four right flow cytometry panels show representative examples of Tim-3+ bulk and CD56 bright, $\mathrm{CD}^{\mathrm{dim}}$ and CD56 ${ }^{\text {neg }}$ NK cells in an HIV-1 negative subject (HIV-), an individual with late primary untreated infection, an untreated chronic HIV-1 progressor, and a HAART-treated HIV-1+ patient. Percentages of Tim-3+ bulk NK cells, and MFI of Tim-3 on CD56 bright NK cells are indicated on the top left of the main panel and on the top right of the CD56 ${ }^{\text {bright }}$ NK cell gate, respectively. (B) Dot plots represent the percentage of Tim-3+ NK cells from 13 healthy individuals and 85 HIV-1-infected subjects (C), including 14 with early untreated HIV-1 infection, 54 with chronic untreated HIV-1 infection (blue, 17 viremic controllers; green, 17 elite controllers; red, 20 untreated progressors), and 17 with HAART-treated HIV-1

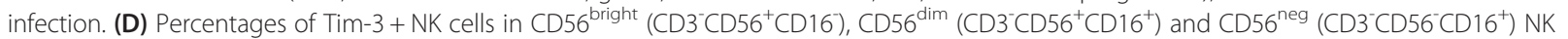
cells in 13 HIV-1 negative and 85 HIV-1-infected subjects. (E) MFI of Tim-3 on CD56 bright NK cells in 13 healthy individuals and 14 subjects with early infection, 54 with chronic untreated HIV-1 infection, including 17 viremic controllers (blue, VC), 17 elite controllers (green, EC), 20 untreated progressors (red, CU), and 17 with HAART-treated HIV-1 infection (CT). Horizontal lines indicate the median percentages. Statistical differences with $p<0.05$ are indicated and were determined using the Mann-Whitney t test to compare phenotype frequencies between two groups.

healthy subjects (Figure 1A and B). Cell surface density of Tim-3 on NK cells, as measured by the mean fluorescence intensity (MFI), trended to be lower in HIV-1 infection compared to HIV-1-negative controls, however the difference did not reach statistical significance (HIV1-infected subjects: median, 497; IQR, 387-622; healthy 
controls: median, 600; IQR, 457.3-805.5; $\mathrm{p}=0.1$ ). A substantial decrease in the number of NK cells expressing Tim-3 was observed as early as in primary HIV-1 infection, and appeared to be partially restored by highly active antiretroviral therapy (HAART) (Figure 1C). The lowest proportions of Tim-3+ NK cells were found in viremic controllers $(\mathrm{p}=0.002$ and $\mathrm{p}=0.02$ compared to healthy controls and untreated progressors, respectively), yet there was an overall high degree of variability in Tim-3 expression among these subjects (median, 48; IQR 38.7-64.3), which could not be attributed to differences in any of the demographic or clinical data analyzed (data not shown). Interestingly, elite controllers had similar percentages of Tim-3+ NK cells (median, 58.2; IQR, 47-62.7) as untreated subjects with chronic viremic HIV-1 infection (median, 62, IQR, 55.1-67).

Functionally distinct NK cell subsets can be defined based on the level of CD56 and CD16 co-expression on NK cells. Consequently, we assessed whether Tim-3 expression differed between $\mathrm{CD} 56^{\text {bright }} \mathrm{CD} 16^{-}, \mathrm{CD} 56^{\mathrm{dim}} \mathrm{CD} 16^{+}$, and $\mathrm{CD} 56^{\mathrm{neg}} \mathrm{CD} 16^{+} \mathrm{NK}$ cell subsets. The observed decrease in Tim-3+ NK cells in HIV-1-infected individuals was mainly driven by a decline in CD56 ${ }^{\mathrm{dim}}$ and $\mathrm{CD} 56^{\text {neg }}$ NK cells expressing Tim-3, whereas no change was observed in the CD56 $6^{\text {bright }}$ compartment (Figure 1D). As observed for bulk NK cells, decreased percentages of Tim3+ CD56 dim and CD56 ${ }^{\text {neg }} \mathrm{NK}$ cells were found in patients with early $(p=0.04$ and not significant, respectively) and untreated chronic infection, (i.e. untreated progressors and controllers) $(\mathrm{p}=0.008$ and 0.01 , respectively) (Additional file 1 ). While proportions of Tim-3+ CD56 $6^{\text {bright }}$ NK cells did not vary between healthy controls and HIV-1-infected individuals, this subset of NK cells expressed significantly higher levels of Tim-3 during the early phase of the infection and in individuals with untreated progressive infection compared to CD56 ${ }^{\text {bright }} \mathrm{NK}$ cells in states of suppressed viremia, such as in HIV controllers, HAART-treated HIV-infected individuals and healthy subjects (Figure 1A and E). Increased expression of Tim-3 on NK cells might be partly explained by elevated percentages of Tim-3+ CD56 $6^{\text {bright }} \mathrm{NK}$ cells in early and progressive infection (Additional file 1).

CD4+ T-cell counts positively correlated with the proportions of bulk $(p=0.04$, Spearman $r=0.28)$ and $\mathrm{CD}^{\mathrm{dim}}(\mathrm{p}=0.03$, Spearman $\mathrm{r}=0.31)$ NK cells expressing Tim-3 in subjects with untreated chronic progressive and controlled HIV-1 infection (Additional file 2). In untreated subjects with chronic HIV-1 infection and active HIV replication (i.e. detectable viral loads), percentages of Tim-3+ bulk $(\mathrm{p}=0.006$, Spearman $\mathrm{r}=0.46)$ and $\mathrm{CD}_{56}{ }^{\mathrm{dim}}(\mathrm{p}=0.004$, Spearman $\mathrm{r}=0.48)$ NK cells were even more strongly associated with CD4+ T-cell counts. No statistically significant associations were observed with HIV-1 viral loads (data not shown).
Taken together, untreated HIV-1 infection was associated with an early and persisting decrease in percentages of circulating CD56 ${ }^{\text {dim }}$ and CD $56^{\text {neg }}$ NK cells expressing Tim-3. Loss of Tim-3+ NK cells over time was more pronounced in untreated subjects (i.e. untreated chronic progressors and controllers) with low $\mathrm{CD} 4+\mathrm{T}$ cell counts. Tim-3 was transiently upregulated on the immunoregulatory CD56 ${ }^{\text {bright }}$ subset of NK cells during the early phase of HIV-1 infection, possibly reflecting a cytokine-induced maturation process as previously demonstrated in vitro [21]. High surface expression of Tim-3 on NK cells persisted on CD56 $6^{\text {bright }}$ NK cells in untreated individuals with progressive HIV infection, while no difference was observed in individuals with low or no viremia present (HAART-treated subjects, controllers and healthy individuals).

\section{High expression of Galectin-9 in primary HIV-1 infection}

To further dissect the potential mechanisms leading to alterations in Tim-3 expression on NK cells, we examined whether differential plasma concentration or cellular expression of Gal-9, a Tim-3 ligand, accounts for the changes observed in early and chronic HIV-1 infection. Plasma Gal-9 levels were more than 6-times higher in late primary HIV-1 infection and twice higher in chronically infected HIV-1-positive subjects than in healthy controls (Figure 2A). There was no difference in soluble Gal-9 levels between HAART-treated and untreated subjects with progressive or controlled HIV infection. Likewise, the differences between HIV-negative and HIV-1 -positive populations did not reach statistical significance. Elevated concentrations of Gal-9 in HIV-1 -infected subjects were positively correlated with viremia (Figure 2B) and negatively correlated with CD4+ T-cell counts (Figure 2C).

Gal-9 is produced by a wide range of epithelial and immune cells [29]. In order to identify the predominant source of cellular Gal-9, we assessed its intracellular levels by flow cytometry in different immune cell subsets, including CD4+ and CD8+ T lymphocytes, NK cells, monocytes, myeloid and plasmacytoid dendritic cells (mDCs and pDCs, respectively) in a subset of 32 HIV-positive and 9 HIV negative controls (Figure 3A and B). In healthy individuals, Gal-9 trended to have higher intracellular expression in monocytes and DCs than in the other lymphocyte subsets examined (Figure 3C). However, in individuals with early HIV-1 infection, intracellular Gal-9 levels were significantly upregulated in all analyzed peripheral blood mononuclear cells (PBMCs), with monocytes and DCs displaying the highest expression levels. In contrast, intracellular Gal-9 levels in immune cells from subjects with chronic HIV-1 infection were similar to those in healthy individuals (data not shown). In line with the correlation observed between plasma Gal-9 levels and 
viral load, intracellular levels of Gal-9 in CD4+ T cells, CD8+ T cells, NK cells, monocytes, and mDCs all positively correlated with viral load in subjects with HIV-1 infection (Figure 3D). This association was maintained even after exclusion of elite controllers from the analysis (data not shown). Thus, levels of the soluble form of Gal-9 were overall increased in the plasma of HIV-1-infected individuals, specifically during the early phase of HIV-1 infection, coinciding with the early upregulation of Gal-9 in all PBMC subsets analyzed. Cellular expression levels of Gal9 also correlated with the aforementioned parameters of disease progression.

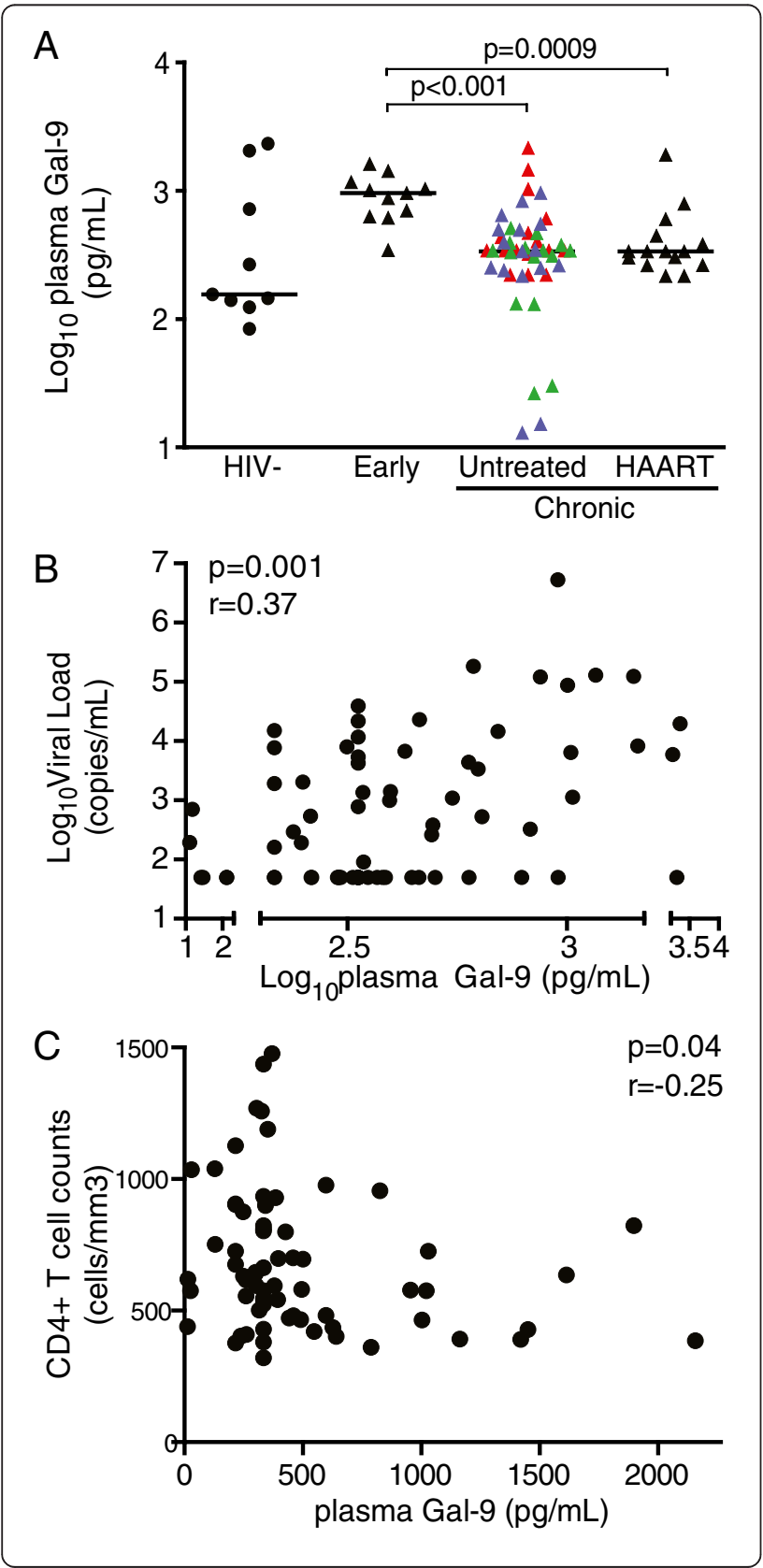

Figure 2 High plasma Galectin-9 concentration in early HIV-1 infection. (A) Dot plots represent the logarithmic concentration of soluble Gal-9 in the plasma of 9 healthy individuals, 11 subjects with early untreated HIV-1 infection, 15 with HAART-treated HIV-1 infection, and 47 untreated individuals with chronic HIV-1 infection, including 16 viremic controllers (blue), 15 elite controllers (green), and 16 subjects with chronic untreated progressive HIV-1 infection (red), as determined by ELISA. (B) Positive correlation between the logarithmic viral load and the logarithmic concentration of soluble Gal-9 in the plasma of 73 HIV-1 individuals, including 11 subjects with early infection, 16 viremic controllers, 15 elite controllers, 16 subjects with chronic untreated, and 15 with treated HIV-1 infection. (C) Inverse correlation between the CD4+ T cell counts and the concentration of soluble Gal-9 in the plasma of $69 \mathrm{HIV}-1$ individuals, including 7 subjects with early infection, 16 viremic controllers, 15 elite controllers, 16 subjects with chronic untreated, and 15 with treated HIV-1 infection. CD4-T cell counts were not available for 4 subjects with early HIV-1 infection at the exact date of the sample draw.

Exposure to soluble Gal-9 triggers NK cell degranulation and Tim-3 downmodulation

Cross-linking of Tim-3 has been shown to inhibit NK cell cytotoxic functions in vitro [21]. Based on our observation of increased levels of Gal-9 in natural HIV-1 infection, we sought to next investigate whether Gal-9 could modulate NK cell function in vitro. To address this question, we compared NK cell function following treatment with soluble Gal-9 to that upon exposure to major histocompatibility complex (MHC)-deficient target cells (i.e. K562 cells). Incubation with Gal-9 triggered NK cell activation, as measured by CD107a surface expression, which occurred concomitantly with a decreased surface expression of Tim-3 (Figure 4A). Percentages of Tim-3+ NK cells were also diminished upon Gal-9 stimulation, although to a lesser extent (data not shown). Treatment with soluble Gal-9 did not lead to a significant increase in production of IFN- $\gamma$ (unstimulated: median, 0.7; IQR 0.42-0.94; Gal-9; median, 1.014; IQR, 0.3893- 2.033), as compared to incubation with K562 cells (median, 9.7; IQR, 5.08- 17.13; $\mathrm{p}=0.008$ vs. unstimulated and $\mathrm{p}=0.004 \mathrm{vs}$. Gal-9). In order to further understand the function executed by Tim-3 in the NK cell response to Gal-9, we analyzed changes in CD107a expression on NK cells bearing high (Tim- $3^{\text {bright }}$, medium $\left(\mathrm{Tim}-3^{\mathrm{dim}}\right)$ or low/no $\left(\mathrm{Tim} 3^{\text {low/neg }}\right)$ levels of Tim-3, and observed that following incubation with Gal9, CD107a upregulation on Tim3 $3^{\text {low/neg }}$ NK cells was enhanced compared to that of Tim- $3^{\text {bright }}$ and Tim $3^{\text {dim }}$ NK cells (Figure 4B). Tim- $3^{\text {bright }}$ NK cells were enriched in CD56 ${ }^{\text {bright }}$ NK cells which might intrinsically have defective degranulation properties. Therefore, we quantified CD107a upregulation on Tim-3 $3^{\text {bright }}$, Tim- $3^{\text {dim }}$ and Tim-3 $3^{\text {low/neg }}$ CD56 $6^{\text {dim }}$ NK cells, and found that upon Gal-9 stimulation, the activity of CD $56^{\text {dim }}$ NK cells expressing high amounts of Tim-3 was significantly 
A
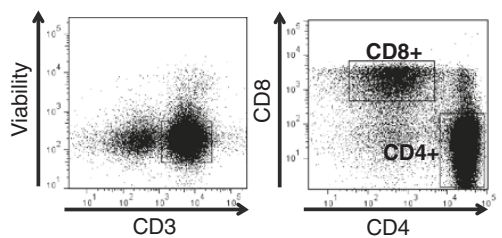

B

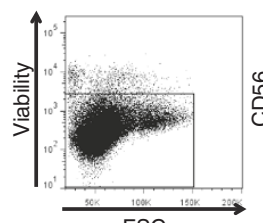

C
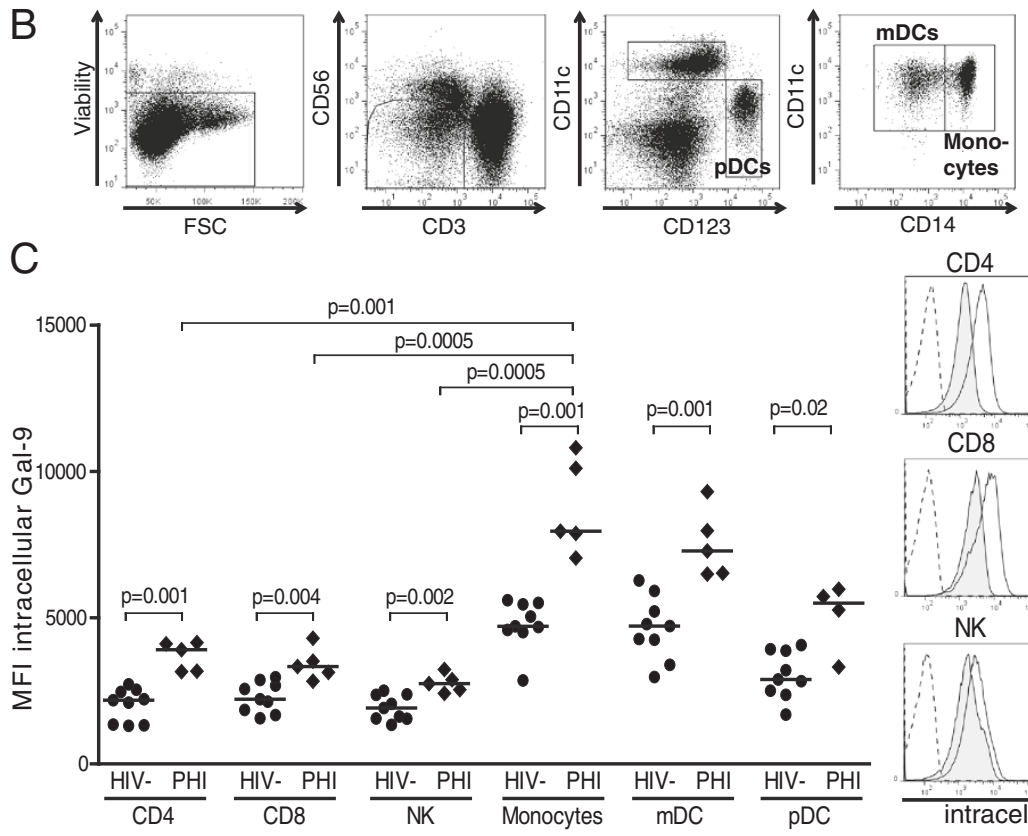

Monocytes

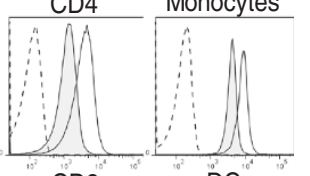

$\mathrm{CD} 8$

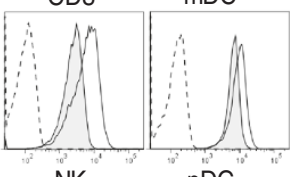

NK
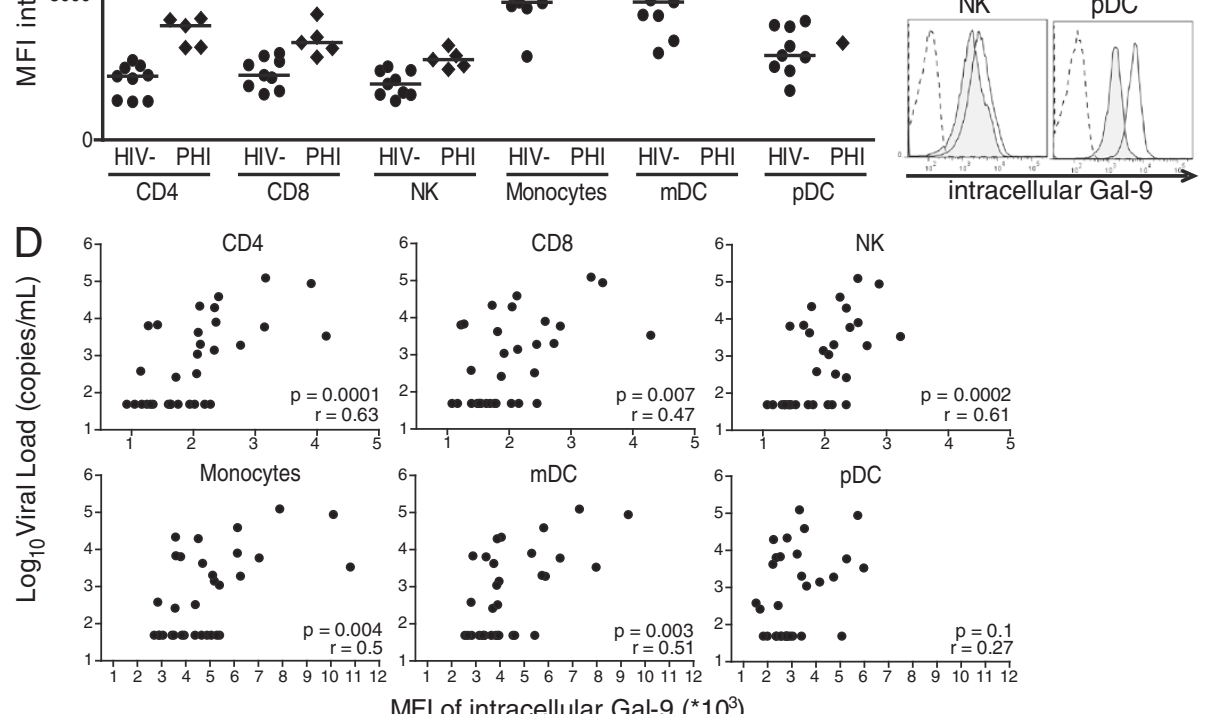

MFI of intracellular Gal-9 $\left({ }^{*} 10^{3}\right)$

Figure 3 Expression of galectin-9 in PBMCs is increased in early HIV-1 infection and correlates with HIV-1 viremia. Flow cytometry gating strategy to analyze intracellular expression of Gal-9 on (A) CD4+ and CD8+ T cells and (B) pDCs, monocytes or mDCs. Gates are set to exclude dead cells (viability marker ${ }^{+}$), and expression of Gal-9 on various lymphocyte subsets is defined by using appropriate fluorescence-minus -one controls. (C) Dot plots display the MFI of intracellular Gal-9 in the indicated immune cell subsets from 9 healthy (HIV-) and 5 untreated subjects with early infection as determined by flow cytometry. Horizontal lines indicate the median percentages. Differences where $p<0.05$ are indicated. Histogram overlays display representative examples of intracellular Gal-9 expression in each lymphocyte subset analyzed in healthy controls (tinted) and in individuals with early HIV-1 infection (transparent) compared to the FMO (dotted line). PHI, early HIV-1 infection (D) Correlations between the logarithmic viral load and the MFI of intracellular Gal-9 in CD4 + T cells, CD8+ T cells, NK cells, monocytes, mDCS and pDCs from a subset of 32 HIV-1-positive individuals, including 4 subjects with early infection, 6 viremic controllers, 6 elite controllers, 9 subjects with chronic untreated, and 7 with chronic treated HIV-1 infection.

reduced compared to those expressing $\operatorname{dim}(\mathrm{p}<0.0001)$ and low $(\mathrm{p}<0.0001)$ levels, showing that CD56 ${ }^{\text {bright }} \mathrm{NK}$ cells were not introducing a bias in our findings (data not shown).
Overall, these data suggest that exposure to soluble Gal-9 increases NK cell degranulation and leads to Tim3 downregulation. This observation would be consistent with a model where circulating Gal-9 mediates Tim-3 

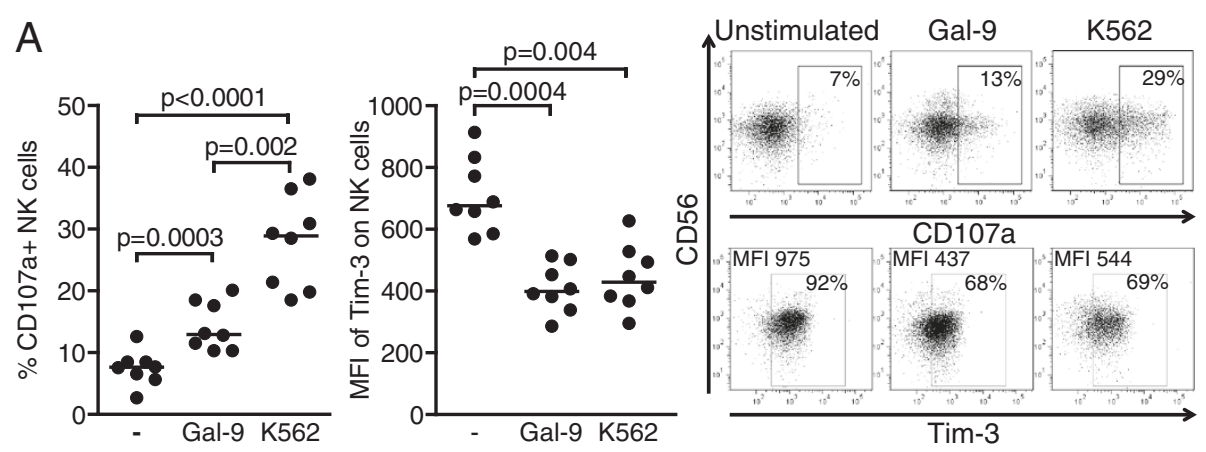

B

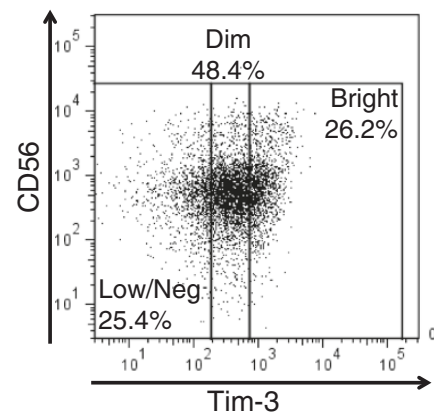

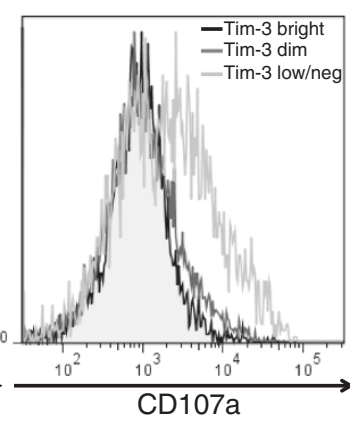

Figure 4 Incubation with soluble Gal-9 increases NK cell function and decreases surface expression of Tim-3. (A) Dot plots represent the percentages of CD107a + NK cells and the MFI of Tim-3 on NK cells from 8 healthy individuals upon pre-activation with $1 \mathrm{ng} / \mathrm{mL}$ of IL-15 and IL-18 overnight followed by stimulation with either $0.9 \mu \mathrm{g} / \mathrm{mL}$ of soluble Gal-9 for another $16 \mathrm{~h}$ or K562 target cells at an effector:target ratio of 10:1 for $6 \mathrm{~h}$. Representative primary flow cytometry panels show CD107a upregulation (upper panel) and Tim-3 expression (lower panel) on NK cells that were left unstimulated, or were activated as indicated. (B) Unstimulated or Gal-9-activated NK cells were divided into Tim-3 $3^{\text {bright }}$, Tim-3 $^{\text {dim }}$ and Tim-3 $3^{\text {low/neg }}$ so that the bright and the low/neg subpopulations each consistently represents about $25 \%$ of the bulk NK cells, and subsequently analyzed for CD107a expression. Representative primary flow panel shows an example of subdivision of NK cells according to Tim-3 expression. Percentages of positive NK cells and median fluorescence intensity are indicated. Histograms display CD107a upregulation in each subset following incubation with soluble Gal-9. Horizontal lines indicate the median percentages. Statistically significant difference reached when $p<0.05$ is indicated.

downmodulation on NK cells, leading to a contraction of the Tim-3-expressing NK cell population in chronically infected HIV-1+ individuals.

\section{Discussion}

An emerging body of data indicates that the Tim-3/Gal9 pathway may play a critical role in the regulation of both adaptive and innate immune mechanisms [20,21,23-29,34-38,40]. In this study, we investigated changes in the expression of the immuno-regulatory receptor Tim-3 on NK cells, and that of its ligand Gal-9 in HIV-1 infection. To our knowledge, this is the first report demonstrating loss of peripheral Tim-3+ NK cells in subjects with early and chronic untreated HIV-1 infection, with lower CD4+ T cell counts in chronically infected subjects expressing decreased percentages of Tim-3+ NK cells (Figure 1 and Additional file 1). While the observed decrease in Tim-3-expressing NK cells did not affect the CD56 ${ }^{\text {bright }}$ NK cell subset, this specific subpopulation displayed an increased surface expression of the receptor during late primary HIV-1 infection, which occurred concomitantly with increased expression of Gal-9, predominantly by monocytes and $\mathrm{mDCs}$ (Figures 2 and 3). Together with previous reports, our data strongly suggest that enhanced exposure to Gal-9 during early HIV-1 infection can lead to NK cell activation, which might be beneficial to early control of HIV-1 replication (Figure 4) [20,35]. Involvement of Tim-3 in early control of HIV-1 infection and subsequent chronic exposure to Gal-9 may eventually lead to a loss of Tim-3 expression on NK cells, resulting in diminished responsiveness to its ligands.

It has been demonstrated that treatment with IL-12 and IL-18 leads to Tim-3 upregulation on CD56 ${ }^{\text {bright }}$ NK cells, and increases the ability of this subset to produce IFN- $\gamma$ in response to Gal-9 $[20,21]$. In line with these results, we show here that Tim-3 surface density is upregulated on peripheral CD56 $6^{\text {bright }}$ NK cells during early HIV-1 infection and in untreated chronic HIV-1 infection, representing populations with high viremia. In contrast to recently published studies, we did not detect 
substantial IFN- $\gamma$ production upon stimulation of NK cells with Gal-9 in vitro. However, our experiments were performed in the presence of IL-15 and IL-18 but without addition of IL-12, and the absence of this key cytokine might account for this discrepancy. Elevated inflammatory cytokine concentrations, including that of IL-12 and IL-18, have been previously described in individuals with early HIV-1 infection [43,44]. Likewise, ongoing viral replication in subjects with progressive HIV1 infection most likely sustains a chronic inflammatory status. In these specific contexts, elevated concentrations of IL-12 and IL-18 might promote upregulation of Tim3 on CD56 ${ }^{\text {bright }}$ NK cells in vivo as observed in our cohorts of subjects with early or progressive untreated HIV-1 infection. Moreover, we observed that early HIV1 infection is characterized by increased plasmatic levels of Gal-9. Altogether, these conditions may result in a Gal-9-induced enhancement of in vivo IFN- $\gamma$ production by NK cells during the primary phase of the infection. Accordingly, in early HIV-1 infection, CD4+ T-cell counts negatively correlated with surface density of Tim-3 on CD56 $6^{\text {bright }}$ NK cells as measured by the MFI (Additional file 3). This association between low CD4+ T-cell counts and high Tim-3 expression on CD56 $6^{\text {bright }}$ NK cells may partly reflect enhanced IFN- $\gamma$-mediated elimination of HIV-1-infected CD4+ T cells. A recent study by Finney et al. also found increased expression of Tim-3 in CD56 ${ }^{\text {high }}$ NK cells from untreated chronic subjects, yet the authors did not observe a significant decrease in percentages of Tim-3+ CD56 ${ }^{\text {low }}$ NK cells [45]. However, low numbers of HIV-1-infected subjects included in this study, use of alternate Tim-3 reagents and particularly, differences in the NK cell classification approach for CD56 ${ }^{\text {high }}$ and CD56 ${ }^{\text {low }}$ NK cells may account for these distinct observations. Thus, our data suggest that increased surface density of Tim-3 on NK cells during early HIV-1 infection, followed by a loss of peripheral blood Tim-3+ subsets of cytotoxic NK cells, may be linked to progressive HIV-1 infection.

Over time, it is likely that constant exposure of Tim-3+ NK cells to Gal-9, which is more abundant in the plasma of individuals with chronic HIV-1 infection than in healthy subjects, contributes to Tim-3 downregulation. Indeed, it has been suggested that both direct and indirect stimulation can trigger internalization of activating NK cell receptors to prevent activation-induced cell death $[46,47]$. While it is clear that in the presence of specific cytokines, the interaction between Tim- 3 and Gal-9 results in enhanced IFN- $\gamma$ production by CD56 $6^{\text {bright }}$ NK cells, it remains to be elucidated whether engagement of Tim-3 triggers NK cell activation and how NK cell function is modulated by changes in Tim-3 expression in the context of viral infections. Gleason and colleagues reported diminished expression of Tim-3 on NK cells from patients undergoing allogeneic hematopoietic stem cell transplantation for the treatment of leukemia, and lower expression correlated with impaired IFN- $\gamma$ production, further supporting a role for Tim-3 signaling in enhancing cytokine production by NK cells [20]. In accordance with this concept, we show that engagement of Tim-3 with soluble Gal-9 triggers NK cell activation and Tim-3 downmodulation. Following exposure to Gal-9, NK cells with the most important CD107a upregulation were those with no or very low Tim-3 surface expression as a consequence of stimulation (Figure 4). These data do not directly exclude the possibility that soluble Gal-9 used to stimulate NK cells competes with the monoclonal antibody for binding to Tim-3, yet the fact that K562-activated NK cells also presented a significant decrease in surface expression of Tim-3 suggests that NK cell activation generally triggers Tim-3 downmodulation. Finally, we assessed whether NK cell activation by Gal-9 is mediated by Tim-3 by adding antibodies directed against this receptor, yet Tim-3 blockade did not significantly alter CD107a expression on NK cells, suggesting that engagement of alternate receptors by Gal-9 might contribute to this effect (Additional file 4). Accordingly, a controversially discussed publication by Leitner et al. recently suggested that Tim-3 does not act as a receptor for Gal-9 [48]. However, this study focused on Tim-3/Gal-9 interaction in $\mathrm{T}$ cells, and therefore caution has to be taken while extrapolating these results to NK cells. In particular, Tim-3 engagement may have distinct outcomes depending on the immune cell type expressing this receptor, suggesting that the nature of the signal mediated by Tim- 3 might depend on the presence of downstream signaling molecules, which differ from one immune cell type to another. Moreover, in the manuscript by Leitner et al., stimulation of Tim-3 by Gal-9 was performed using membrane-bound and not soluble Gal-9, and this difference in methodology might impact the signal and partly explain the discrepancies between the results obtained in this setting compared to previous publications.

While further investigations are warranted to fully understand the effect of Tim-3 on NK cell function in HIV-1 infection, the permanent low expression of this potential co-activating receptor on NK cells may contribute to the previously described loss of NK cell function associated with chronic HIV-1 infection $[41,42]$. In line with this hypothesis, we show that CD56 ${ }^{\text {neg }}$ NK cells, which constitute an anergic subset of NK cells that accumulates in HIV-1 infection [41,42], displayed the lowest levels of Tim-3 expression. An alternative explanation of the observed decreased percentages of peripheral blood Tim3 + CD56 ${ }^{\text {dim }}$ NK cells in HIV-1-infected individuals could be tissue redistribution and recruitment of these highly functional cells into lymphoid tissue compartments, such as lymph nodes or mucosal sites. 
Contrary to our observation in HIV-1 infection, peripheral blood and hepatic NK cells from subjects with chronic HBV infection had increased expression of Tim3 , and blockade of this receptor with an antibody directed at Tim-3 increased NK cell functions, suggesting that Tim-3, alone or in combination with other receptors, can contribute to delivering inhibitory signals [40]. It is conceivable that the NK cell surface concentration of Tim-3 determines whether the signal will be activating or inhibitory, as has been proposed for the immunoregulatory receptor 2B4 [49]. In contrast, other published data reveal that cross-linking with an anti-Tim -3 antibody abrogates cytolytic functions triggered via potent activating NK cell receptors [21]. Overall, the mechanisms underlying Tim-3 signaling appear to be highly complex and remain incompletely understood. It will therefore be critical to assess how natural ligands for Tim-3 modulate NK cell functions.

It was previously shown that individuals with chronic HIV-1 infection and high viral loads ( $>10,000$ copies $/ \mathrm{mL})$ have higher levels of Gal-9 in the plasma compared to those with low viremia [35]. In our study we found that low CD4+ T cell counts and high HIV-1 viral loads were both associated with high concentrations of Gal-9 in the plasma from HIV-1-infected patients (Figure 3). Measurement of intracellular Gal-9 showed that among all lymphocyte subsets analyzed, the ligand for Tim-3 is mainly produced by monocytes and $\mathrm{mDCs}$, and significantly upregulated in these cell types during early HIV1 infection. As it has been demonstrated that Gal-9 can be both secreted and expressed at the surface of antigen presenting cells [24], it will be of paramount importance to evaluate the role of Tim-3/Gal-9 interactions in the cross-talks between NK cells and DCs, and how these impact the HIV-1-specific adaptive immune responses. It is tempting to speculate that engagement of Tim-3 in the mucosa very early in HIV-1 infection may lead to potent NK cell activation, and could limit viral spread.

\section{Conclusions}

To conclude, while recent data indicate the existence of potential Tim-3-independent interactions between Gal-9 and NK cells [50], our study suggests that interactions between Gal-9 and Tim-3 can play a role in regulating NK cell function in HIV-1 infection. Further experiments will be required to determine how Tim-3 signaling pathways in NK cells differ from those identified in $\mathrm{T}$ cells and DCs so far, and how it affects NK cell function in both early and chronic infection. Overall, these data contribute to a better understanding of the innate immune mechanisms displayed in HIV-1 infection, providing a basis for further analysis into the contribution of NK cell receptors in the control of HIV-1 infection.
Notably, molecules that can increase Gal-9 concentration at mucosal sites might enhance early control of HIV-1 replication, as previously suggested [35], and offer a strategy worth exploring for incorporation in future immunotherapeutic interventions or strategic HIV-1 vaccine design.

\section{Methods}

Study subjects $(\mathrm{n}=98)$

The study included 14 individuals identified during untreated early HIV-1 infection (Fiebig stage IV-V), 54 subjects with untreated chronic HIV-1 infection, which included 20 individuals with untreated progressive disease (median viral load, 8137; IQR, 5664-21175), 17 elite controllers with HIV-1 RNA below the limit of detection of standard viral load assays $(<50$ copies $/ \mathrm{mL})$ for at least 1 year ( among the 17 elite controller subjects studied here, viral loads were suppressed for a median of 3.5 (IQR 1.13-7.5) years), 17 viremic controllers with untreated asymptomatic HIV-1 infection (HIV-1 RNA $<2000$ copies $/ \mathrm{mL}$ ), 17 HIV-1-positive individuals HAART-treated with viral loads $<50$ copies $/ \mathrm{mL}$ for $>1$ year (median, 9.1; range, 1.9-15.5), and 13 healthy HIV-1 uninfected controls (Table 1). The study was approved by the Massachusetts General Hospital Institutional Review Board, and written informed consent was obtained from all study participants.

\section{Flow cytometric analysis}

To quantify Tim-3 expression on NK cells, cryopreserved PBMCs were thawed and stained with anti-CD3-Qdot605 (Invitrogen), anti-CD56-A700, anti-CD16-APC-Cy7 (BD Biosciences) and anti-Tim-3-PE (BioLegend, clone F382E2). Gating strategy is outlined in Figure 1A. Intracellular staining of Gal-9 was performed using the Fix \& Perm ${ }^{\circ}$ Medium A and B kit (Invitrogen) and anti-gal-9-PE (BioLegend, clone 9 M1-3) following surface staining with anti-CD3-Qdot605, anti-CD4-Qdot655 (Invitrogen), antiCD56-PECy7, anti-CD16-APC-Cy7, anti-CD11c-APC, anti-CD8a-A700, anti-CD123-PECy5, anti-CD14-Pacific Blue (BD Biosciences). The LIVE/DEAD ${ }^{\circ}$ Fixable Blue Dead Cell Stain Kit was used prior to any surface staining to exclude dead cells (Invitrogen). NK cell populations were defined as lymphocytes that were CD3-negative and included $\mathrm{CD} 56^{\text {bright }}\left(\mathrm{CD}^{-} \mathrm{CD}^{-} 6^{+} \mathrm{CD} 16^{-}\right), \mathrm{CD}^{-6^{\mathrm{dim}}}\left(\mathrm{CD} 3^{-}\right.$ $\left.\mathrm{CD}^{2} 6^{+} \mathrm{CD} 16^{+}\right)$, and $\mathrm{CD} 56^{\text {neg }}\left(\mathrm{CD}^{-} \mathrm{CD} 56^{-} \mathrm{CD} 16^{+}\right)$NK cell subsets. The $\mathrm{mDC}$ population was defined as $\mathrm{CD}^{-} \mathrm{CD} 14^{-}$ $\mathrm{CD}^{-} 6^{-} \mathrm{CD} 11 \mathrm{c}^{+} \mathrm{CD} 123^{-}$, the $\mathrm{pDC}$ population as $\mathrm{CD}^{-} \mathrm{CD} 14^{-}$ $\mathrm{CD} 56^{-} \mathrm{CD} 11 \mathrm{c}^{-} \mathrm{CD} 123^{+}$, and the monocyte population as $\mathrm{CD}^{-} \mathrm{CD} 14^{+} \mathrm{CD} 56^{-} \mathrm{CD} 11 \mathrm{c}^{+} \mathrm{CD} 123^{-}$(Figure $4 \mathrm{~B}$ ). Data were acquired on LSRII 4 laser system using FacsDiva ${ }^{\mathrm{Tw}}$ software version 8.8.3 (BD Biosciences). The frequency and phenotypes of NK cells, CD4+ and CD8+ T cells, monocytes, 
mDCs and pDCs were defined using the Flow $\mathrm{JO}^{\mathrm{Tm}}$ software version 7.6.5 (Treestar, Ashland, OR).

\section{Quantification of Gal-9 in plasma}

Plasma specimen collected at the same time points as PBMC samples were available for a subset of 82 study participants (15 elite and 16 viremic controllers, 16 individuals with chronic untreated HIV-1 infection, 15 HIV1-positive treated individuals, 11 individuals identified during late primary HIV-1 infection, and 9 healthy HIV1 uninfected controls). The plasma concentration of Gal-9 was quantified using an ELISA kit for soluble human Gal-9 (Uscn Life Science Inc.), according to the manufacturer's protocol. This kit allows for the detection of Gal-9 with a dynamic range of 7.8 to $500 \mathrm{pg} / \mathrm{mL}$.

\section{Flow cytometric analysis of NK cell function}

NK cell activation was quantified after overnight prestimulation of fresh PBMCs with $1 \mathrm{ng} / \mathrm{mL}$ of IL-15 and IL-18, followed by incubation with either MHC-devoid K562 cells at an effector-to-target cell ratio of 10:1 for $6 \mathrm{~h}$ as previously described [51] or with $0.9 \mu \mathrm{g} / \mathrm{mL}$ of soluble Gal-9 (R\&D) for $16 \mathrm{~h}$ in $1 \mathrm{~mL}$ of RPMI-1640 supplemented with $10 \%$ fetal bovine serum, $2 \mathrm{mM}$ L-glutamine, $100 \mu \mathrm{g} / \mathrm{ml}$ streptomycin and $100 \mathrm{U} / \mathrm{ml}$ penicillin, $10 \mu \mathrm{l} / \mathrm{ml}$ anti-CD107a-PE-Cy5 antibody (BD Biosciences), $5 \mu \mathrm{g} / \mathrm{ml}$ brefeldin A (Sigma) and $0.3 \mu \mathrm{g} / \mathrm{ml}$ monensin (Golgi stop; BD Biosciences). Medium alone served as the negative control, and PMA/ionomycin (2.5 and $0.5 \mu \mathrm{g} / \mathrm{mL}$, respectively) served as the positive control. PBMCs were then stained with anti-CD3-Pacific Blue, anti-CD56-PE-Cy7, anti-CD16-APC-Cy7 (BD Biosciences) and anti-Tim-3-PE (Biolegend) antibodies, fixed, permeabilized (as described above) and finally stained for intracellular IFN- $\gamma$ using anti-IFN- $\gamma$-FITC antibody (BD Biosciences). Multiparameter flow cytometric analysis was performed on LSRII 4 laser instrument (BD Biosciences). The frequency and phenotypes of NK cells were defined using FlowJo ${ }^{\text {тM }}$ version 7.6.5 (Treestar).

\section{Statistical analyses}

The non-parametric Kruskal-Wallis test was used to compare phenotype frequencies and functional differences among patient groups when more than two groups were involved, and was followed by a Dunns Multiple Comparison post-test. The Mann-Whitney $\mathrm{t}$ test was used to compare phenotype frequencies and functional differences between two groups. The $p$-values were twosided. Spearman's rank correlation was used for correlation analysis. $p$-values of $<0.05$ were considered significant. Statistical analyses were performed using the GraphPad Prism $^{\mathrm{Ts}}$ software version 5.04.

\section{Additional files}

\begin{tabular}{|c|}
\hline $\begin{array}{l}\left.\text { D56 }{ }^{+} \mathrm{CD} 16^{-}\right), \mathrm{Tim}^{-3} \mathrm{CD}^{\mathrm{dim}}\left(\mathrm{CD} \mathrm{3}^{-} \mathrm{CD} 56^{+} \mathrm{CD} 16^{+}\right) \text {and Tim-3+ } \\
\text { D56 }{ }^{\text {neg }}\left(\mathrm{CD} 3^{-} \mathrm{CD} 56^{-} \mathrm{CD} 16^{+}\right) \text {NK cells in } 13 \text { HIV-1 negative (HIV-) } \\
\text { nd } 14 \text { subjects with early untreated HIV-1 infection (Early), } 20 \\
\text { ntreated progressors (red, CU), } 17 \text { viremic controllers (blue, VC), } \\
7 \text { elite controllers (green, EC), and } 17 \text { with HAART-treated HIV-1 } \\
\text { fection (CT). Horizontal lines indicate the median percentages. }\end{array}$ \\
\hline $\begin{array}{l}\text { ntreated chronic HIV-1 infection and available clinical data } \\
\text { natching the day of PBMCs and plasma sample collection), includin } \\
7 \text { elite controllers (green), } 17 \text { viremic controllers (blue) and } 17 \\
\text { dividuals with untreated chronic progressive infection (red). }\end{array}$ \\
\hline $\begin{array}{l}\text { dditional file 3: Inverse correlation between the MFI of Tim-3 on } \\
\text { D56 } 6^{\text {bright }} \text { NK cells and CD4+ T cell counts in } 9 \text { subjects with early } \\
\text { IV-1 infection and available clinical data matching the date of the } \\
\text { BMCs sample used for the quantification of Tim-3 on NK cells. }\end{array}$ \\
\hline $\begin{array}{l}\text { dditional file 4: Downregulation of Tim-3 (upper graph) and } \\
\text { pregulation of CD107a (lower graph) on NK cells stimulated with } \\
\text { al-9 in the presence of Tim-3 blocking antibodies. PBMCs from } 3 \\
\text { ealthy individuals were incubated overnight in the presence of } 1 \mathrm{ng} / \mathrm{mL} \\
\text { IL-12 and } 10 \mathrm{ng} / \mathrm{mL} \text { of IL-18 prior to incubation with Gal-9 (1 ug/mL) or } \\
62 \text { cells (effector:target ratio of } 10: 1 \text { ) in the presence or absence of anti- }\end{array}$ \\
\hline
\end{tabular}

\section{Abbreviations}

NK: Natural killer; HIV-1: Human immunodeficiency virus type 1; Tim-3: T-cell immunoglobulin and mucin domain-containing molecule 3; Gal-9: Galectin9; HAART: Highly active antiretroviral therapy; DC: Dendritic cell; HCV: Hepatitis C virus; HBV: Hepatitis B virus; IFN- $\gamma$ : Interferon-gamma; IQR: Interquartile range; MFI: Mean fluorescence intensity; mDC: myeloid dendritic cell; pDC: plasmacytoid dendritic cell; PBMCs: Peripheral blood mononuclear cells; MHC: Major histocompatibility complex.

\section{Competing interests}

The authors declare that they have no competing interests.

\section{Authors' contributions}

MMA, MA, SJ and UM designed experiments; UM, WG, SJ, KR and JR performed experiments; UM and SJ analyzed the data; SJ wrote the paper, MMA, MA, UM and WG edited manuscript drafts. IT and AP provided essential reagents. All authors read and approved the final manuscript.

\section{Acknowledgements}

We are grateful to the patients and the healthy volunteers for their blood donations. We thank Mike Waring and Adam Chicoine for excellent assistance with flow cytometry through the Harvard University Center for AIDS Research (HU CFAR) Immunology Core at the Ragon Institute.

This work was supported in part by research funding from MGH/ECOR (Physician Scientist Development Award to MMA and Fund for Medical Discovery to SJ) and the NIH NIAID (KO8 Al074405 to MMA, R01 Al067031 and P01 Al074415 to MA). This research was further supported by the Terry and Susan Ragon Foundation and the Harvard University Center for AIDS Research (CFAR), an NIH funded program (P30 Al060354) which is supported by the following $\mathrm{NIH}$ Co-Funding and Participating Institutes and Centers: NIAID, NCl, NICHD, NHLBI, NIDA, NIMH, NIA, FIC, and OAR.

\section{Author details}

${ }^{1}$ Ragon Institute of MGH, MIT and Harvard, 400 Technology Square, Cambridge, MA 02139, USA. ${ }^{2}$ Heinrich-Pette-Institut, Leibniz Institute for Experimental Virology, Hamburg, Germany.

Received: 22 February 2013 Accepted: 13 June 2013 Published: 18 July 2013 


\section{References}

1. 2012 UNAIDS Report on the Global AIDS Epidemic. [http://www.unaids. org/en/media/unaids/contentassets/documents/epidemiology/2012/gr2012/ 20121120 UNAIDS Global_Report_2012 en.pdf]

2. Martin MP, Gao X, Lee JH, Nelson GW, Detels R, Goedert JJ, Buchbinder S, Hoots K, Vlahov D, Trowsdale J, et al: Epistatic interaction between KIR3DS1 and HLA-B delays the progression to AIDS. Nat Genet 2002, 31:429-434.

3. Martin MP, Qi Y, Gao X, Yamada E, Martin JN, Pereyra F, Colombo S, Brown EE, Shupert WL, Phair J, et al: Innate partnership of HLA-B and KIR3DL1 subtypes against HIV-1. Nat Genet 2007, 39:733-740.

4. Alter G, Martin MP, Teigen N, Carr WH, Suscovich TJ, Schneidewind A, Streeck H, Waring M, Meier A, Brander C, et al: Differential natural killer cell-mediated inhibition of HIV-1 replication based on distinct KIR/HLA subtypes. J Exp Med 2007, 204:3027-3036.

5. Alter G, Rihn S, Walter K, Nolting A, Martin M, Rosenberg ES, Miller JS, Carrington M, Altfeld M: HLA class I subtype-dependent expansion of KIR3DS1+ and KIR3DL1+ NK cells during acute human immunodeficiency virus type 1 infection. J Virol 2009, 83:6798-6805.

6. Boulet S, Kleyman M, Kim JY, Kamya P, Sharafi S, Simic N, Bruneau J, Routy JP, Tsoukas CM, Bernard NF: A combined genotype of KIR3DL1 high expressing alleles and HLA-B*57 is associated with a reduced risk of HIV infection. AIDS 2008, 22:1487-1491.

7. Boulet S, Sharafi S, Simic N, Bruneau J, Routy JP, Tsoukas CM, Bernard NF: Increased proportion of KIR3DS1 homozygotes in HIV-exposed uninfected individuals. AIDS 2008, 22:595-599.

8. Boulet S, Song R, Kamya P, Bruneau J, Shoukry NH, Tsoukas CM, Bernard NF: HIV protective KIR3DL1 and HLA-B genotypes influence NK cell function following stimulation with HLA-devoid cells. I Immunol 2010, 184:2057-2064.

9. Parsons MS, Boulet S, Song R, Bruneau J, Shoukry NH, Routy JP, Tsoukas CM, Bernard NF: Mind the gap: lack of association between KIR3DL1*004/ HLA-Bw4-induced natural killer cell function and protection from HIV infection. J Infect Dis 2010, 202(Suppl 3):S356-360.

10. Alter G, Heckerman D, Schneidewind A, Fadda L, Kadie CM, Carlson JM, Oniangue-Ndza C, Martin M, Li B, Khakoo Sl, et al: HIV-1 adaptation to NK-cell-mediated immune pressure. Nature 2011, 476:96-100.

11. Strbo N, de Armas L, Liu H, Kolber MA, Lichtenheld M, Pahwa S: IL-21 augments natural killer effector functions in chronically HIV-infected individuals. AIDS 2008, 22:1551-1560.

12. O'Connell KA, Han Y, Williams TM, Siliciano RF, Blankson JN: Role of natural killer cells in a cohort of elite suppressors: low frequency of the protective KIR3DS1 allele and limited inhibition of human immunodeficiency virus type 1 replication in vitro. J Virol 2009, 83:5028-5034.

13. Paust $\mathrm{S}$, von Andrian UH: Natural killer cell memory. Nat Immunol 2011 , 12:500-508

14. Andrews DM, Estcourt MJ, Andoniou CE, Wikstrom ME, Khong A, Voigt $\mathrm{V}$, Fleming P, Tabarias H, Hill GR, van der Most RG, et al: Innate immunity defines the capacity of antiviral T cells to limit persistent infection. J Exp Med 2010, 207:1333-1343.

15. Cooper MA, Fehniger TA, Fuchs A, Colonna M, Caligiuri MA: NK cell and DC interactions. Trends Immunol 2004, 25:47-52.

16. Robbins SH, Bessou G, Cornillon A, Zucchini N, Rupp B, Ruzsics Z, Sacher T, Tomasello E, Vivier E, Koszinowski UH, Dalod M: Natural killer cells promote early CD8 T cell responses against cytomegalovirus. PLoS Pathog 2007, 3:e123.

17. Waggoner SN, Cornberg M, Selin LK, Welsh RM: Natural killer cells act as rheostats modulating antiviral T cells. Nature 2012, 481:394-398.

18. Lanier LL: NK cell recognition. Annu Rev Immunol 2005, 23:225-274.

19. Khademi M, Illes Z, Gielen AW, Marta M, Takazawa N, Baecher-Allan C, Brundin L, Hannerz J, Martin C, Harris RA, et al: T Cell Ig- and mucindomain-containing molecule-3 (TIM-3) and TIM-1 molecules are differentially expressed on human Th1 and Th2 cells and in cerebrospinal fluid-derived mononuclear cells in multiple sclerosis. J Immunol 2004, 172:7169-7176.

20. Gleason MK, Lenvik TR, McCullar V, Felices M, O'Brien MS, Cooley SA Verneris MR, Cichocki F, Holman CJ, Panoskaltsis-Mortari A, et al: Tim-3 is an inducible human natural killer cell receptor that enhances interferon gamma production in response to galectin-9. Blood 2012, 119:3064-3072.

21. Ndhlovu LC, Lopez-Verges S, Barbour JD, Jones RB, Jha AR, Long BR, Schoeffler EC, Fujita T, Nixon DF, Lanier LL: Tim-3 marks human natural killer cell maturation and suppresses cell-mediated cytotoxicity. Blood 2012, 119:3734-3743.

22. Zhu C, Anderson AC, Kuchroo VK: TIM-3 and its regulatory role in immune responses. Curr Top Microbiol Immunol 2011, 350:1-15.
23. Monney L, Sabatos CA, Gaglia JL, Ryu A, Waldner H, Chernova T, Manning S, Greenfield EA, Coyle AJ, Sobel RA, et al: Th1-specific cell surface protein Tim-3 regulates macrophage activation and severity of an autoimmune disease. Nature 2002, 415:536-541.

24. Li H, Wu K, Tao K, Chen L, Zheng Q, Lu X, Liu J, Shi L, Liu C, Wang G, Zou W: Tim-3/galectin-9 signaling pathway mediates T-cell dysfunction and predicts poor prognosis in patients with hepatitis B virus-associated hepatocellular carcinoma. Hepatology 2012, 56:1342-1351.

25. Jones RB, Ndhlovu LC, Barbour JD, Sheth PM, Jha AR, Long BR, Wong JC, Satkunarajah M, Schweneker M, Chapman JM, et al: Tim-3 expression defines a novel population of dysfunctional T cells with highly elevated frequencies in progressive HIV-1 infection. J Exp Med 2008, 205:2763-2779.

26. Sakhdari A, Mujib S, Vali B, Yue FY, Macparland S, Clayton K, Jones RB, Liu J, Lee EY, Benko E, et al: Tim-3 Negatively Regulates Cytotoxicity in Exhausted CD8(+) T Cells in HIV Infection. PLoS One 2012, 7:e40146.

27. Golden-Mason L, Palmer BE, Kassam N, Townshend-Bulson L, Livingston S, McMahon BJ, Castelblanco N, Kuchroo V, Gretch DR, Rosen HR: Negative immune regulator Tim-3 is overexpressed on T cells in hepatitis $C$ virus infection and its blockade rescues dysfunctional CD4+ and CD8+ T cells. $J$ Virol 2009, 83:9122-9130.

28. Vali B, Jones RB, Sakhdari A, Sheth PM, Clayton K, Yue FY, Gyenes G, Wong D, Klein MB, Saeed S, et al: HCV-specific T cells in HCV/HIV co-infection show elevated frequencies of dual Tim-3/PD-1 expression that correlate with liver disease progression. Eur J Immunol 2010, 40:2493-2505.

29. Zhu C, Anderson AC, Schubart A, Xiong H, Imitola J, Khoury SJ, Zheng XX, Strom TB, Kuchroo VK: The Tim-3 ligand galectin-9 negatively regulates $T$ helper type 1 immunity. Nat Immunol 2005, 6:1245-1252.

30. DeKruyff RH, Bu X, Ballesteros A, Santiago C, Chim YL, Lee HH, Karisola P, Pichavant M, Kaplan GG, Umetsu DT, et al: T cell/transmembrane, Ig, and mucin-3 allelic variants differentially recognize phosphatidylserine and mediate phagocytosis of apoptotic cells. J Immunol 2010, 184:1918-1930.

31. Nakayama M, Akiba H, Takeda K, Kojima Y, Hashiguchi M, Azuma M, Yagita $\mathrm{H}$, Okumura K: Tim-3 mediates phagocytosis of apoptotic cells and cross-presentation. Blood 2009, 113:3821-3830.

32. Chiba S, Baghdadi M, Akiba H, Yoshiyama H, Kinoshita I, Dosaka-Akita H, Fujioka Y, Ohba Y, Gorman JV, Colgan JD, et al: Tumor-infiltrating DCs suppress nucleic acid-mediated innate immune responses through interactions between the receptor TIM-3 and the alarmin HMGB1. Nat Immunol 2012, 13:832-842.

33. Wada J, Kanwar YS: Identification and characterization of galectin-9, a novel beta-galactoside-binding mammalian lectin. J Biol Chem 1997, 272:6078-6086

34. Bi S, Earl LA, Jacobs L, Baum LG: Structural features of galectin-9 and galectin-1 that determine distinct T cell death pathways. J Biol Chem 2008, 283:12248-12258.

35. Elahi S, Niki T, Hirashima M, Horton H: Galectin-9 binding to Tim-3 renders activated human CD4+ T cells less susceptible to HIV-1 infection. Blood 2012, 119:4192-4204.

36. Anderson AC, Anderson DE, Bregoli L, Hastings WD, Kassam N, Lei C Chandwaskar R, Karman J, Su EW, Hirashima M, et al: Promotion of tissue inflammation by the immune receptor Tim-3 expressed on innate immune cells. Science 2007, 318:1141-1143.

37. Sabatos CA, Chakravarti S, Cha E, Schubart A, Sanchez-Fueyo A, Zheng XX, Coyle AJ, Strom TB, Freeman GJ, Kuchroo VK: Interaction of Tim-3 and Tim3 ligand regulates $T$ helper type 1 responses and induction of peripheral tolerance. Nat Immunol 2003, 4:1102-1110.

38. Bi S, Hong PW, Lee B, Baum LG: Galectin-9 binding to cell surface protein disulfide isomerase regulates the redox environment to enhance T-cell migration and HIV entry. Proc Natl Acad Sci USA 2011, 108:10650-10655.

39. Cao E, Zang X, Ramagopal UA, Mukhopadhaya A, Fedorov A, Fedorov E, Zencheck WD, Lary JW, Cole JL, Deng H, et al: T cell immunoglobulin mucin-3 crystal structure reveals a galectin-9-independent ligandbinding surface. Immunity 2007, 26:311-321.

40. Ju Y, Hou N, Meng J, Wang X, Zhang X, Zhao D, Liu Y, Zhu F, Zhang L, Sun $W$, et al: $T$ cell immunoglobulin- and mucin-domain-containing molecule3 (Tim-3) mediates natural killer cell suppression in chronic hepatitis B. J Hepatol 2010, 52:322-329.

41. Alter G, Teigen N, Davis BT, Addo MM, Suscovich TJ, Waring MT, Streeck $H_{\text {, }}$ Johnston MN, Staller KD, Zaman MT, et al: Sequential deregulation of NK cell subset distribution and function starting in acute HIV-1 infection. Blood 2005, 106:3366-3369. 
42. Mavilio D, Lombardo G, Benjamin J, Kim D, Follman D, Marcenaro E, O'Shea MA, Kinter A, Kovacs C, Moretta A, Fauci AS: Characterization of CD56-/CD16+ natural killer (NK) cells: a highly dysfunctional NK subset expanded in HIVinfected viremic individuals. Proc Natl Acad Sci USA 2005, 102:2886-2891.

43. Gay C, Dibben O, Anderson JA, Stacey A, Mayo AJ, Norris PJ, Kuruc JD, Salazar-Gonzalez JF, Li H, Keele BF, et al: Cross-sectional detection of acute HIV infection: timing of transmission, inflammation and antiretroviral therapy. PLoS One 2011, 6:e19617.

44. Stacey AR, Norris PJ, Qin L, Haygreen EA, Taylor E, Heitman J, Lebedeva M, DeCamp A, Li D, Grove D, et al: Induction of a striking systemic cytokine cascade prior to peak viremia in acute human immunodeficiency virus type 1 infection, in contrast to more modest and delayed responses in acute hepatitis B and C virus infections. J Virol 2009, 83:3719-3733.

45. Finney CA, Ayi K, Wasmuth JD, Sheth PM, Kaul R, Loutfy M, Kain KC, Serghides L: HIV Infection Deregulates Tim-3 Expression on Innate Cells; Combination Antiretroviral Therapy Results in Partial Restoration. J Acquir Immune Defic Syndr 2013, 63:161-167.

46. Alter G, Jost S, Rihn S, Reyor L, Nolan B, Ghebremichael M, Bosch R, Altfeld M, Lauer G: Reduced frequencies of NKp30 + NKp46+, CD161+ and NKG2D + NK cells in acute HCV infection may predict viral clearance. J Hepatol 2010.

47. Lanier LL: Up on the tightrope: natural killer cell activation and inhibition. Nat Immunol 2008, 9:495-502.

48. Leitner J, Rieger A, Pickl WF, Zlabinger G, Grabmeier-Pfistershammer K, Steinberger P: TIM-3 Does Not Act as a Receptor for Galectin-9. PLoS Pathog 2013, 9:e1003253.

49. Chlewicki LK, Velikovsky CA, Balakrishnan V, Mariuzza RA, Kumar V: Molecular basis of the dual functions of 2B4 (CD244). J Immunol 2008, 180:8159-8167.

50. Golden-Mason L, McMahan RH, Strong M, Reisdorph R, Mahaffey S, Palmer BE, Cheng L, Kulesza C, Hirashima M, Niki T, Rosen HR: Galectin-9 functionally impairs natural killer (NK) cells in humans and mice. J Virol 2013, 87:4835-4845.

51. Alter $\mathrm{G}$, Malenfant JM, Altfeld M: CD107a as a functional marker for the identification of natural killer cell activity. J Immunol Methods 2004, 294:15-22.

doi:10.1186/1742-4690-10-74

Cite this article as: Jost et al.: Dysregulated Tim-3 expression on natural killer cells is associated with increased Galectin-9 levels in HIV-1 infection. Retrovirology 2013 10:74.

\section{Submit your next manuscript to BioMed Central and take full advantage of:}

- Convenient online submission

- Thorough peer review

- No space constraints or color figure charges

- Immediate publication on acceptance

- Inclusion in PubMed, CAS, Scopus and Google Scholar

- Research which is freely available for redistribution

Submit your manuscript at www.biomedcentral.com/submit 